\title{
Construção de uma biblioteca de fragmentos de anticorpos monoclonais de galinhas com cadeia única (scFv) por phage display com reatividade cruzada para estirpes heterólogas do vírus da bronquite infecciosa aviária
}

\author{
Construction of an avian single chain monoclonal antibodies (scFv) library by phage display \\ that cross-reacted with heterologous avian infectious bronchitis virus strains
}

\author{
Camila Cesário Fernandes ${ }^{\mathrm{I}}$ Aline Gonçalves Caetano ${ }^{\mathrm{I}}$ Mariana Costa Mello Gonçalves ${ }^{\mathrm{I}}$ \\ Maria de Fátima Silva Montassier ${ }^{I}$ Aliandra Maura Gibertoni ${ }^{\mathrm{I}}$ Hélio José Montassier ${ }^{\mathrm{II}}$
}

RESUMO

Anticorpos monoclonais constituem a base de vários testes usados na detecção e na identificação de antígenos. Nesse contexto, tais imuno-reagentes têm sido extensivamente empregados na identificação de estirpes virais envolvidas na etiologia de surtos de bronquite infecciosa a campo, permitindo o aperfeiçoamento das técnicas de detecção e caracterização antigênica do vírus da bronquite infecciosa das galinhas (VBI). No presente estudo, uma biblioteca de fragmentos de anticorpos de galinha originalmente preparada por phage display contra a estirpe vacinal (H120) do VBI foi usada para a seleção de fragmentos de anticorpos recombinantes com reatividade cruzada para as estirpes heterólogas IBVPR01 e IBVPR05, isoladas de surtos a campo no Brasil e a estirpe SE-17, isolada nos Estados Unidos. Após três ciclos de panning, foi identificado, pelo ELISA, um conjunto de 15 anticorpos scFV expressos em fagos e com reatividade cruzada para essas mesmas estirpes do VBI. A análise por Western-blotting revelou que dois desses clones apresentavam fagos expressando fragmentos de anticorpos monoclonais com reatividade cruzada para a nucleoproteína $N$ das três estirpes do VBI e também para a forma recombinante dessa nucleoproteína derivada da estirpe M41. Concluindo, os fragmentos de anticorpos monoclonais recombinantes $s c F v-N$ produzidos em fagos interagem com um epítopo mais conservado da proteína $N$ do VBI e apresentam um grande potencial para utilização na detecção e no diagnóstico direto desse vírus.

Palavras-chave: vírus da bronquite infecciosa, anticorpo monoclonal, nucleoproteína, estirpes de campo, scFv.

\begin{abstract}
Monoclonal antibodies are the basis of various techniques used for antigen detection or characterization, and their use is specially recommended for the identification of viral strains involved in the etiology of infectious bronchitis outbreaks. These antibodies are homogeneous, highly specific and fully characterizable, allowing the improvement of immunological techniques detection and antigenic characterization of avian infectious bronchitis virus strains (IBV). A phage display library was used, which was prepared previously against the IBV vaccine strain (H120) for the selection of new scFv antibody fragments specific for heterologous IBV strains isolated from outbreaks in Brazil (IBVPR01, IBVPR05) and USA (SE-17). After three cycles of panning, a set of $15 \mathrm{scFv}$ antibodies were expressed in phages and cross-reacted in ELISA with these three viral strains. Western-blotting analysis showed that two of the clones were expressing $s c F v$ specific for the nucleoprotein of these IBV strains, as well as to the recombinant form of this protein derived from M41. In conclusion, the recombinant fragments of monoclonal antibodies expressed in phage have a great potential for future use in immunodiagnostic techniques and to study the evolution of infectious bronchitis virus.
\end{abstract}

Key words: infectious bronchitis virus, monoclonal antibody, nucleoprotein, field strains, scFv.

\section{INTRODUÇÃO}

A bronquite infecciosa é uma enfermidade aguda e altamente infecciosa do trato respiratório superior de galinhas. Essa enfermidade tem distribuição

IFaculdade de Ciências Agrárias e Veterinárias (FCAV), Universidade Estadual Paulista (UNESP), Campus de Jaboticabal, Jaboticabal, SP, Brasil.

II Departamento de Patologia Veterinária, Laboratório de Imunologia e Virologia, prédio da Microbiologia. Via de Acesso Prof. Paulo Donato Castellane, s/n, 14884-900, Jaboticabal, SP, Brasil. E-mail: heliojm@fcav.unesp.br. Autor para correspondência. 
mundial e se configura em um dos maiores problemas sanitários e econômicos para a avicultura (CAVANAGH \& GELB, 2008). O vírus da bronquite infecciosa (VBI) é o agente etiológico da doença e pertence à ordem Nidovirales, à família Coronaviridae e ao gênero Coronavirus do grupo 3, o qual inclui apenas coronavírus aviários. Esse vírus possui envelope lipoproteico e genoma constituído por uma fita de RNA simples, não segmentada, com sentido positivo. São codificadas quatro proteínas estruturais: a glicoproteína de espícula (S), a glicoproteína de membrana (M), a pequena proteína de membrana $(\mathrm{E}) \mathrm{e}$ a proteína de nucleocapsídeo (N) (CAVANAGH, 2007; DIFÁBIO \& ROSSINI, 2000).

Diversas alterações podem ocorrer na composição, na estrutura e nas propriedades antigênicas dessas proteínas, em decorrência de fenômenos de mutação e recombinação que conferem elevada variabilidade genética e antigênica ao VBI. A consequência disso é o isolamento contínuo de estirpes variantes, que causam a quebra da imunidade conferida pelas estirpes vacinais e dificultam o diagnóstico (CAVANAGH, 2007).

A utilização de anticorpos monoclonais fornece uma ferramenta de grande relevância na detecção e caracterização antigênica do VBI. Há ainda algumas técnicas como a reação de imunoflorescência e ELISA, em que o uso de anticorpos monoclonais para antígenos específicos desse vírus, como a nucleoproteína $\mathrm{N}$, facilita e garante a rapidez na detecção desse patógeno viral em amostras teciduais de aves suspeitas de infecção (DE WIT, 2000).

A produção de anticorpos monoclonais tem sido feita predominantemente por meio da técnica de hibridoma, que apresenta desvantagens, como a fácil contaminação do cultivo celular e consequente perda do hibridoma, além do sacrifício de camundongos (MILSTEIN, 1986). Uma alternativa para essas dificuldades é a tecnologia de phage display, que conduz a criação de uma biblioteca de apresentação de fragmentos de anticorpos monoclonais ( $\mathrm{scFv}$ ) fusionados a proteínas de bacteriófagos, e esta é selecionada para o antígeno desejado (DAVIES, et al., 1995; AZZAZY \& HIGHSMITH, 2002).

As aves apresentam vantagens na produção de anticorpos monoclonais pela técnica de phage display, pois, em seu repertório gênico, para a produção de imunoglobulinas, existe apenas um gene VH e um gene VL funcionais, assim apenas um par de iniciadores é necessário para a amplificação de cada uma dessas regiões gênicas (ANDRIS-WIDHOPF, 2000). Nesse sentido, verifica-se que poucos estudos foram realizados para o desenvolvimento de anticorpos monoclonais recombinantes produzidos em galinhas contra patógenos aviários. Na verdade, encontram-se apenas os trabalhos de SAPATS et al. (2003, 2006), nos quais foram obtidos fragmentos de anticorpos monoclonais contra estirpes clássicas e muito virulentas do vírus da doença de Gumboro, e os estudos de CAETANO (2009) e CAETANO et al. (2009), nos quais foram preparados anticorpos monoclonais recombinantes contra antígenos da estirpe vacinal H120 do VBI por phage display.

No presente estudo, foi utilizada uma biblioteca de fragmentos de anticorpos monoclonais anteriormente preparada por phage display (CAETANO, et al., 2009) para a seleção de fragmentos de anticorpos monoclonais recombinantes com reatividade cruzada para as estirpes IBVPR01, IBVPR05 e SE-17, heterólogas à estirpe vacinal, tendo sido obtidos e caracterizados fragmentos de anticorpos monoclonais expressos em fagos com reatividade cruzada para epítopos conservados da proteína $\mathrm{N}$ dessas estirpes do VBI.

\section{MATERIAL E MÉTODOS}

As três diferentes estirpes do VBI (IBVPR01, IBVPR05 e SE-17) foram multiplicadas na cavidade alantoide de ovos embrionados, livres de patógenos específicos (SPF) por inoculação (GELB \& JACKWOOD, 1998) e posteriormente purificadas por ultra centrifugação em gradientes contínuos e descontínuos de sacarose (CARDOSO, et al., 1996).

A biblioteca de fragmentos de anticorpos scFv previamente preparada com a estirpe H120 de referência vacinal do VBI (CAETANO, et al., 2009) foi recuperada por meio do crescimento das células transformantes até a fase exponencial, em que foram infectadas com o fago auxiliar M13K07 (GE Healthcare) numa multiplicidade de infecção (moi) de 5:1, sendo seguidas as recomendações de SAPATS et al. (2003) para a cultura e para o panning e tendo sido usada uma mistura da suspensão purificada das três estirpes do VBI (IBVPR01, IBVPR05 e SE-17), na concentração de aproximadamente $4 \mu \mathrm{g} \mathrm{mL}^{-1}$ de proteínas virais, como antígenos de fase sólida.

A avaliação da biblioteca de fragmentos de anticorpos $\mathrm{scFv}$ expressos em fagos foi realizada primeiramente por meio do método indireto de ELISA, tendo sido seguido o protocolo descrito por CARDOSO et al. (1996). Em síntese, uma mistura das suspensões purificadas do conjunto das três estirpes do VBI (IBVPR01, IBVPR05 e SE-17) a $4 \mu \mathrm{g} \mathrm{mL}^{-1}$ foi usada para adsorção na superfície de microplacas (Costar, Corning). As demais etapas foram realizadas em 
conformidade com o protocolo descrito por CARDOSO et al. (1996), com exceção de que foram usados dois anticorpos reveladores, o primeiro constituído pelos anticorpos policlonais de coelho contra o fago M13 (GE Healthcare), e o segundo o conjugado imunoenzimático constituído por anticorpos de cabra contra IgG de coelho, com a enzima peroxidase (SigmaAldrich). No final, a reação foi bloqueada com $\mathrm{HCl} 2 \mathrm{~N}$, e realizou-se a leitura das absorbâncias a 490nm. Segundo o módulo de expressão Recombinant Phage Antibody System (GE Healthcare), eram considerados positivos os valores de D.O. acima de 0,2. Como controle positivo, foram usados anticorpos policlonais dos soros de galinhas hiperimunizadas com essas estirpes virais e, como controle negativo, um conjunto de amostras de soro de aves SPF, mantidas em isoladores.

Os anticorpos monoclonais $\mathrm{scFv}$ selecionados previamente no ELISA para reagir contra as proteínas virais das três estirpes do VBI (IBVPR01, IBVPR05 e SE-17) foram analisados pela técnica de Western-blotting, conforme os procedimentos gerais descritos por SAPATS et al. (2003, 2006). Foi feita também uma análise complementar, pelo Westernblotting, das proteínas presentes na suspensão concentrada das três estirpes do VBI usadas na seleção dos scFvs, e a proteína $\mathrm{N}$ recombinante da estirpe M41 do VBI que foi expressa em $\boldsymbol{E}$. coli (GIBERTONI, et al., 2009), para melhor avaliar o fragmento scFv que apresentou maior reatividade no ELISA (clone C5P1) como anticorpo primário. Os procedimentos desse ensaio seguiram o mesmo protocolo descrito anteriormente.

As sequências nucleotídicas do clone C5P1 foram determinadas a partir dos oligonucleotídeos iniciadores $D$-sense e $D$-antisense descritos no manual do fagomídio pCANTAB5E (GE Healthcare). O protocolo da reação de sequenciamento foi realizado de acordo com o descrito pelo fabricante do Kit Big Dye Terminator Cycle Sequencing Ready Reaction (Perkin-Elmer Applied Biosystems), sendo conduzido em sequenciador ABI PRISM 3700 DNA Analyzer (Applied Biosystems). A montagem final das sequências de nucleotídeos, a tradução para a sequência de aminoácidos e os alinhamentos múltiplos iniciais foram feitos pelo programa Bioedit v.7.0.5. As sequências finais de nucleotídeos e de aminoácidos foram então submetidas ao BLASTN, a fim de definir os alinhamentos de maior significância para posterior alinhamento final pelo programa CLUSTALW.

\section{RESULTADOS}

Após três ciclos de panning contra as três estirpes de campo do VBI - IBVPR01, IBVPR05 e SE-17, foi obtida uma biblioteca de $10^{5}$ clones, tendo sido separados $5 \times 10^{2}$ clones para serem testados no ELISA. Quinze desses clones expressando scFv em fagos apresentaram reatividades $\geq 0,2$, com os antígenos presentes na suspensão purificada das estirpes IBVPR01, IBVPR05 e SE-17 (Figura 1).

Os três fragmentos de anticorpos $\mathrm{scFv}$ que revelaram as maiores reatividades no ELISA (C5P1, $\mathrm{C} 1 \mathrm{P} 2$ e F10P2) foram submetidos ao ensaio de Western blotting para avaliação da especificidade frente às proteínas estruturais do VBI. Destes, apenas dois (derivados dos clones C5P1 e C1P2) apresentaram reatividade para a proteína de nucleocapsídeo $(\mathrm{N})$ do VBI (Figura 2), e o terceiro clone não demonstrou, nesse ensaio, reatividade para nenhuma das proteínas do VBI, provavelmente em razão de sua reatividade comparativamente menor no ELISA (Figura 1).

O clone C5P1, por apresentar maior reatividade no ELISA e no Western blotting contra a proteína $\mathrm{N}$ do $\mathrm{VBI}$, foi selecionado para avaliação complementar de sua especificidade. Foram detectadas reatividades de intensidade moderada a forte, com relação às preparações de nucleoproteínas das estirpes heterólogas IBVPR01, IBVPR05 e SE-17 e também com a proteína $\mathrm{N}$ recombinante da estirpe M41 do VBI produzida em $\boldsymbol{E}$. coli (GIBERTONI, et al., 2009), confirmando a especificidade antigênica desse fragmento de anticorpo recombinante para um epítopo linear e conservado da proteína $\mathrm{N}$ do VBI (Figura 3). A estirpe M41 pertence ao mesmo sorotipo da estirpe H120, o qual difere das estirpes heterólogas (IBVPR01, IBVPR05 e SE-17) que foram usadas para o panning e a seleção inicial da biblioteca que deu origem a esse anticorpo recombinante.

A análise das sequências deduzidas de aminoácidos do gene codificador do fragmento $\mathrm{scFv}$ aqui produzido revelou maior similaridade na análise pelo BLAST com a sequência de aminoácidos de um fragmento de anticorpo scFv obtido por SAPATS et al. (2003) contra o vírus da doença de Gumboro. Ficou evidente que as principais trocas de aminoácidos se concentram nas regiões CDRs de VH e de VL, atingindo com menor frequência as regiões framework (FR), em razão da entrada de pseudogenes nessas regiões, o que confere a variabilidade entre as moléculas de anticorpos de diferentes especificidades em aves (Figura 4).

\section{DISCUSSÃO}

Neste estudo, uma biblioteca de fragmentos de anticorpos monoclonais, que foi originalmente 


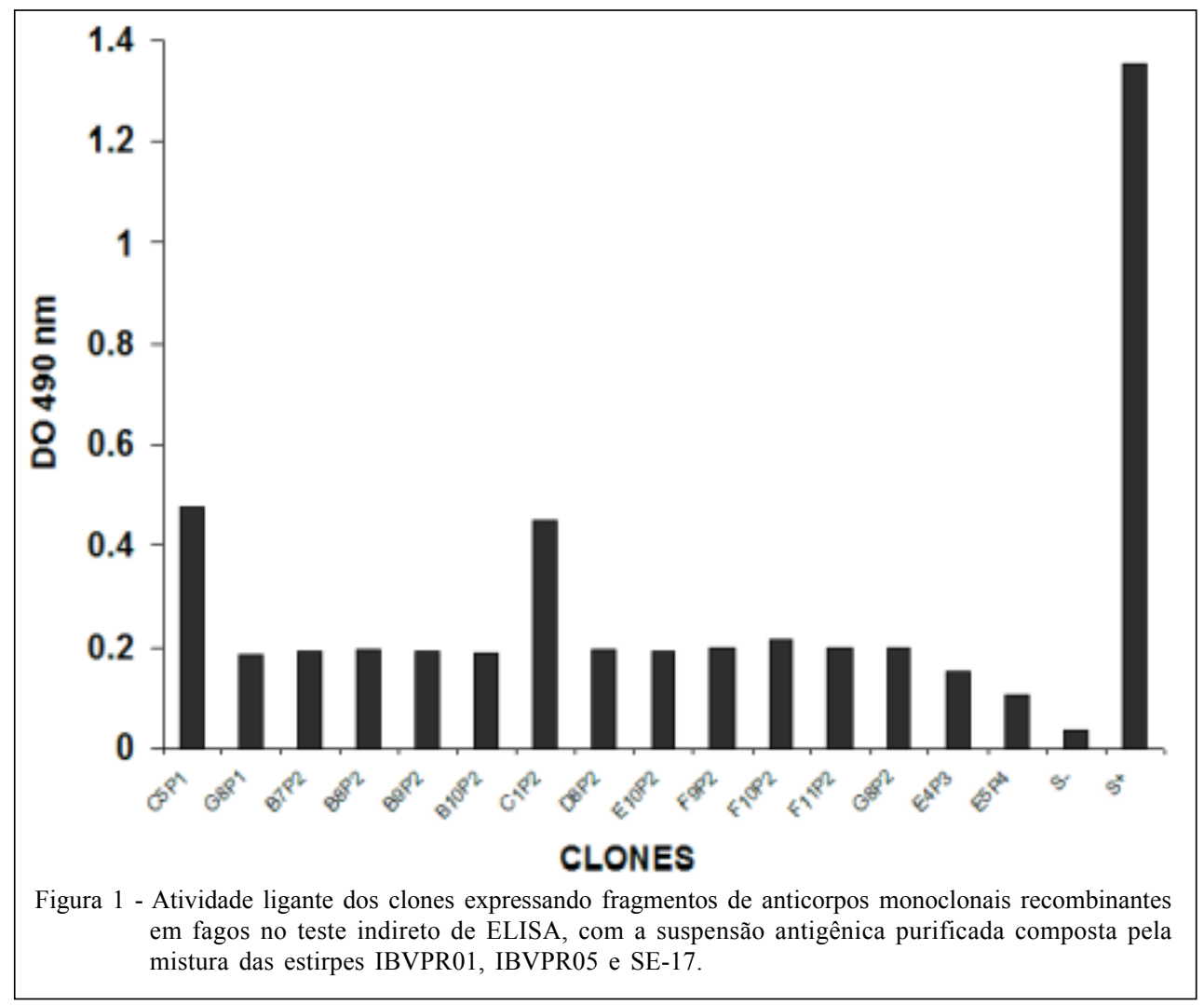

preparada a partir de células do baço de aves hiperimunizadas contra a estirpe de referência vacinal
H120 do VBI, foi utilizada para selecionar anticorpos com reatividade cruzada para três estirpes variantes

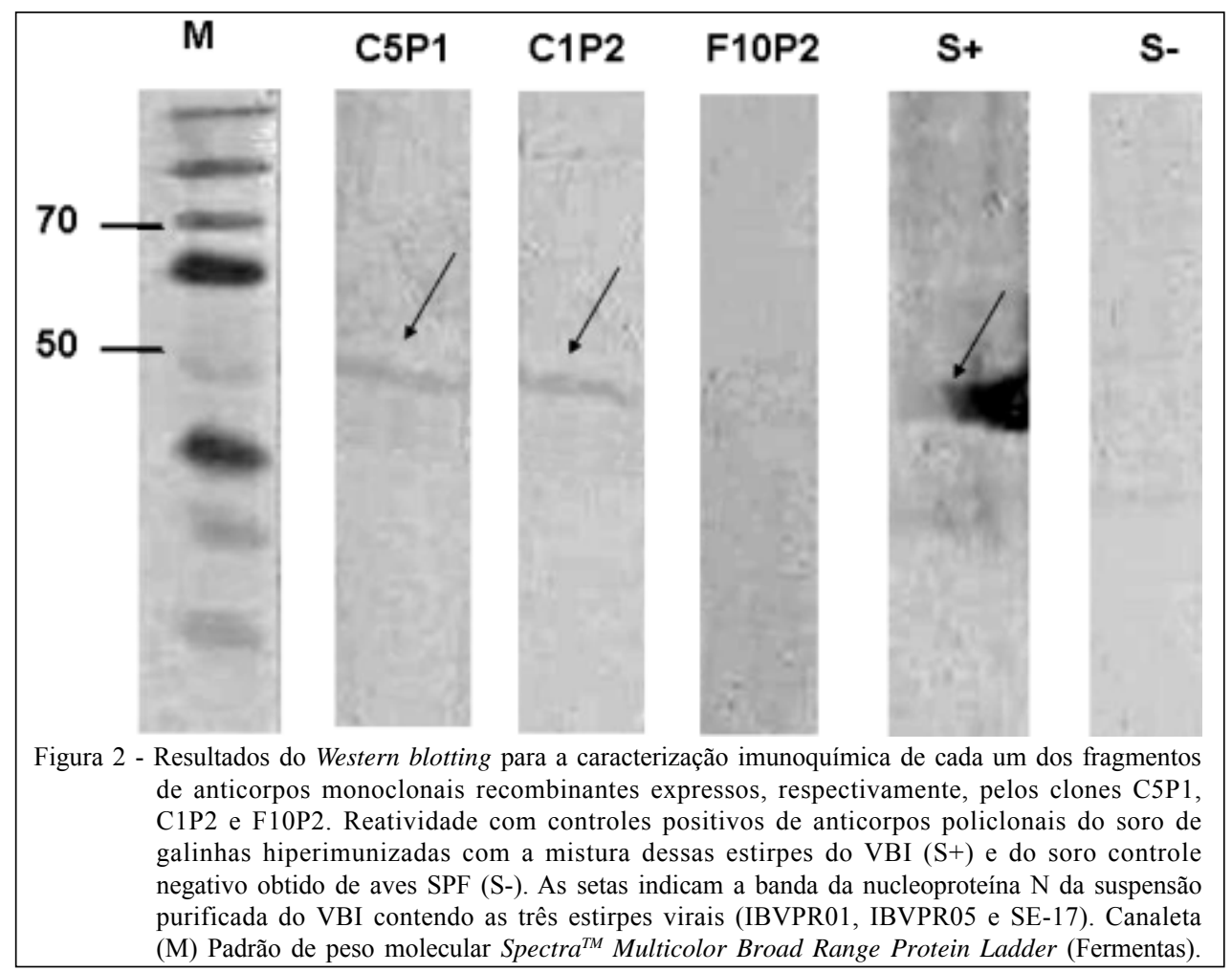

Ciência Rural, v.40, n.6, jun, 2010. 


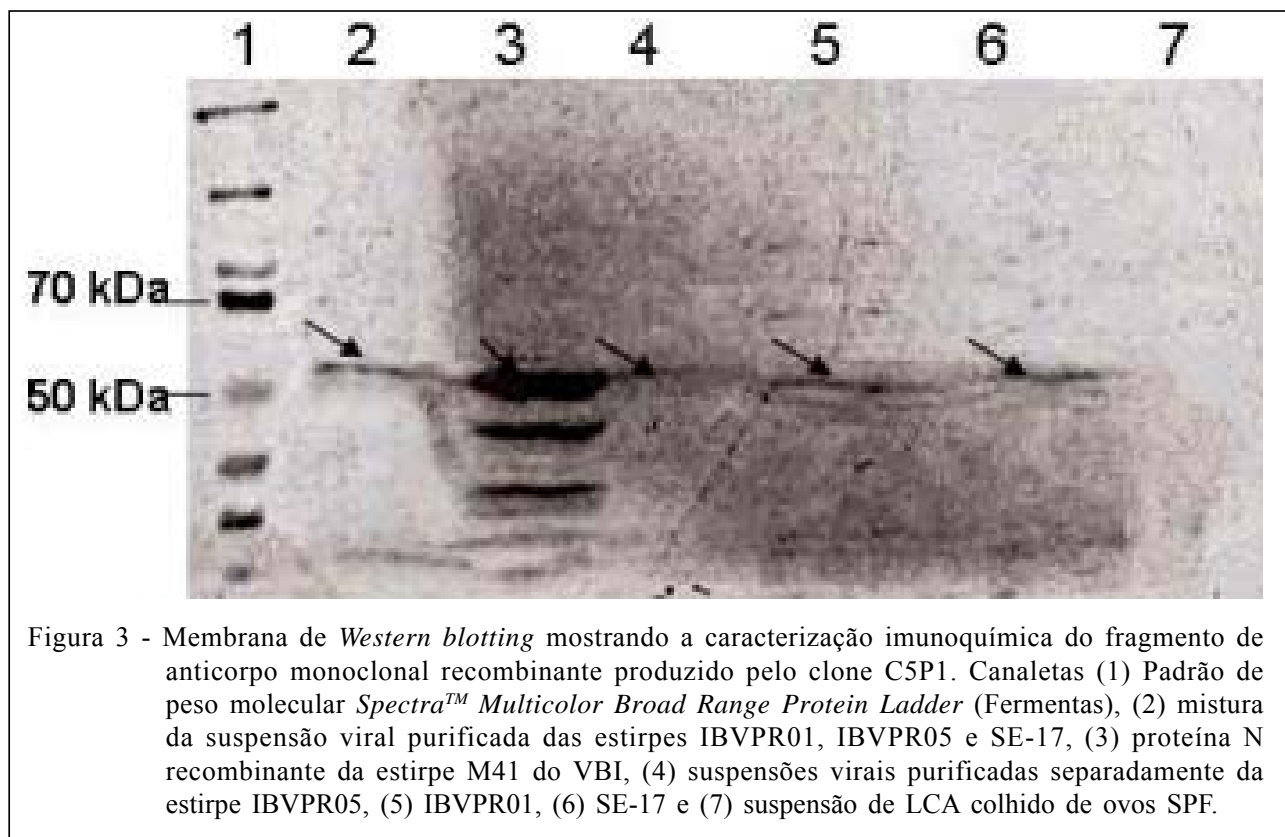

heterólogas do VBI, sendo duas delas isoladas de surtos a campo no Brasil (IBVPR01 e IBVPR05), e outra isolada dos Estados Unidos (SE-17).

É interessante destacar que os fragmentos de anticorpos monoclonais recombinantes obtidos neste estudo demonstraram a capacidade de reagir com a nucleoproteína de três diferentes estirpes do VBI. Resultado similar foi atingido em outro conjunto de fragmentos de anticorpos monoclonais obtidos a partir da construção da biblioteca originalmente preparada contra a estirpe H120 do VBI (CAETANO, 2009; CAETANO, et al., 2009).

Apesar disso, não foi possível caracterizar ainda para qual sítio ou epítopo da proteína $\mathrm{N}$ eles estão direcionados, apenas se supõe que não se tratam dos mesmos epítopos-alvo dos fragmentos produzidos por CAETANO et al. (2009), já que a análise de alinhamento das sequências deduzidas de aminoácidos dos genes desses anticorpos recombinantes revelou grandes diferenças entre cada um deles. Em relação a isso, sabe-se que os epítopos imunodominantes da nucleoproteína N do VBI estão agrupados em três regiões principais compreendidas entre os resíduos de aminoácidos 1 a 50, 175 a 240 e 310 a 409, (SEAH, et al., 2000), podendo-se supor que uma delas contenha o epítopo-alvo do fragmento $\mathrm{scFv}$ produzido neste estudo.

Ademais, a proteína $\mathrm{N}$ está, na partícula do VBI, intimamente relacionada com o RNA genômico e apresenta uma estrutura altamente conservada, com cerca de 94 a 99\% de identidade entre as várias estirpes do VBI (CAVANAGH, 2007). Foi demonstrado ainda que esta é uma proteína altamente imunogênica, sendo, por conseguinte, capaz de induzir a produção de anticorpos contra antígenos mais conservados do grupo do VBI e, ainda, de linfócitos $\mathrm{T}$ efetores específicos, sobretudo com ação citotóxica (WILLIAMS, et al, 1992; SEO, et al. 1997; SEAH, et al., 2000).

Dessa forma, a proteína $\mathrm{N}$ do VBI e os anticorpos a ela dirigidos reúnem um número significativo de atributos para se constituírem em imuno-reagentes de eleição para a deteç̧ão desse vírus ou de anticorpos antivirais específicos. Portanto, a utilização de anticorpos monoclonais contra essa proteína viral é de grande valor para a detecção direta do VBI em amostras teciduais suspeitas de infecção, por meio de técnicas de imunofluorescência, imunoperoxidase ou de ELISA (DE WIT, 2000; NDIFUNA, et al., 1998).

A construção de bibliotecas de fragmentos de anticorpos $\mathrm{scFv}$ recombinantes com reatividade cruzada para estirpes heterólogas à estirpe de referência vacinal H120 do VBI, pela técnica de phage display, oferece um método alternativo e eficaz na produção de fragmentos de anticorpos monoclonais recombinantes contra esse vírus, que podem ser muito úteis para o desenvolvimento de métodos mais rápidos de diagnóstico laboratorial do VBI, bem como em estudos relacionados à persistência ou não de epítopos mais conservados desse vírus durante o seu processo de evolução, como este aqui encontrado para a nucleoproteína $\mathrm{N}$. 


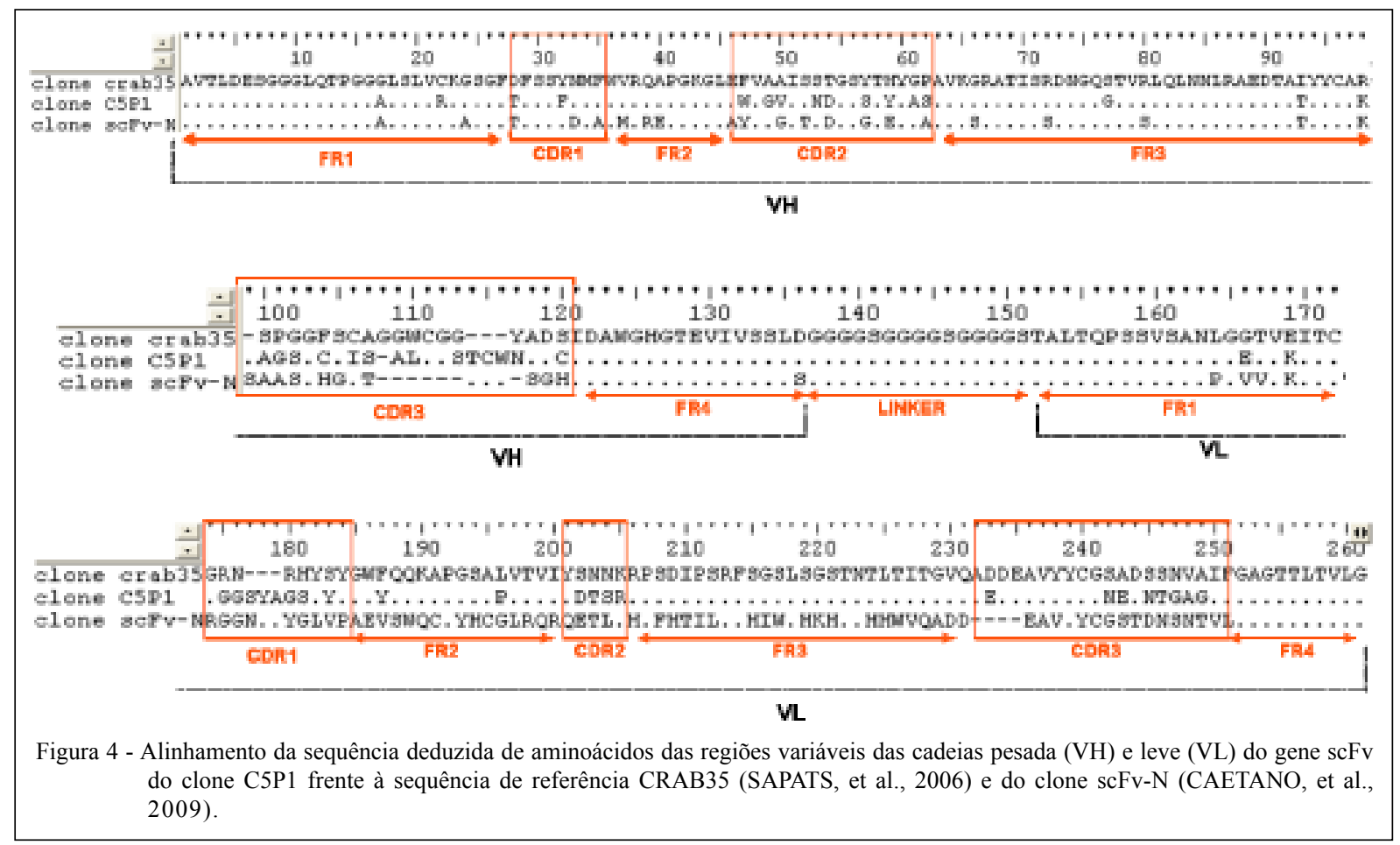

\section{AGRADECIMENTOS}

Os autores agradecem à Fundação de Amparo à Pesquisa do Estado de São Paulo (FAPESP), (processo nº 07/ 57902-5 e 01/14650-3), ao Conselho Nacional de Pesquisa CNPq (proc. 477140/2003-3) e à Empresa MERIAL Saúde Animal.

\section{REFERÊNCIAS}

ANDRIS-WIDHOPF, J. Methods for the generation of chicken monoclonal antibody fragments by phage display. J Immunol Methods, v.242, p.159-181, 2000. Disponível em: $<$ linkinghub.elsevier.com/retrieve/pii/S0022175900002210>. Acesso em: 28 ago. 2007. doi:10.1016/S0022-1759(00)00221-0.

AZZAZY, H.M.E.; HIGHSMITH, J.R.W.E. Phage display technology: clinical applications and recent innovations. Clin Biochem, v.35, p.425-445, 2002. Disponível em: $<$ linkinghub.elsevier.com/retrieve/pii/S0009912002003430>. Acesso em: 05 set. 2007. doi:10.1016/S0009-9120(02)00343-0.

CAETANO, A.G. et al. Construction and expression of $\mathrm{scFv}$ antibody fragment specific for infectious bronchitis virus in Escherichia coli. Vet Immunol Immunopathol, v.128, p.245, 2009. Disponível em: <linkinghub.elsevier.com/retrieve/ pii/S0165242708004741>. Acesso em: 15 jul. 2009. doi:10.1016/j.vetimm.2008.10.075.

CAETANO, A.G. Produção de anticorpos monoclonais contra o virus da bronquite infecciosa das galinhas pela técnica de phage display. 2009. 115f. Tese (Doutorado em Microbiologia Agropecuária) - Curso de Pós-graduação em Microbiologia Agropecuária, Universidade Estadual Paulista, SP.
CARDOSO, T.C. et al. Evaluation of an indirect ELISA method for the detection of chicken antibodies against infectious bronchitis virus. Revista de Microbiologia, v.27, p.64-69, 1996.

CAVANAGH, D. Coronavirus avian infectious bronchitis virus. Vet Res, v.38, p.281-297, 2007. Disponível em: $<$ www.vetres.org/articles/vetres/pdf/2007/02/v06178.pdf $>$. Acesso em: 03 março 2008. doi: 10.1051/vetres:2006055.

CAVANAGH, D.; GELB, Jr, J. Infectious bronchitis. In: SAIF, L.J. (Ed.). Diseases of poultry. Ames: Blackwell Publishing, 2008. p.117-135.

DAVIES, E.L. et al. Selection of specific phage-display antibodies using libraries derived from chicken immunoglobulin genes. $\mathbf{J}$ Immunol Methods, v.186, p.125-35, 1995. Disponível em: <www.ncbi.nlm.nih.gov/pubmed/7561141>. Acesso em: 15 set. 2008. doi:10.1016/0022-1759(95)00143-X.

DE WIT, J.J. Detection of infectious bronchitis virus. Avian Pathol, v.29, p.71-77, 2000. Disponível em: <www.informaworld.com/.../ content $\sim \mathrm{db}=$ all $\sim$ content $=\mathrm{a} 713651150>$. Acesso em: 16 fev. 2009 . doi: $10.1080 / 03079450094108$.

DI FÁBIO, J; ROSSINI, L.I. Bronquite infecciosa das galinhas. In: BERCHIERI, J. R.; MACARI, M. (Ed.). Doença das aves. Campinas: FACTA, 2000. p.293-300.

GELB, Jr, J.; JACKWOOD, M.W. Infectious bronchitis. In: SWAYNE, D.E. (Ed.). A laboratory manual for the isolation and identification of avian pathogens. 4.ed. Florida: Rose Printing, 1998. p.169-174.

Ciência Rural, v.40, n.6, jun, 2010. 
GIBERTONI, A.M. et al. Cloning, expression and characterization of nucleocapsid protein from infectious bronchitis vírus in Escherichia coli. Vet Immunol Immunophatol, v.128, p.243, 2009. Disponível em: $<$ linkinghub.elsevier.com/retrieve/pii/S0165242708004716>. Acesso em: 15 jul. 2009. doi:10.1016/j.vetimm.2008.10.072.

MILSTEIN, C. Overview: monoclonal antibodies. In: WEIRD, D.M. (Ed.). Handbook of experimental immunology: applications of immunological methods in biomedical sciences. Oxford: Blackwell Science, 1986. 2390p.

NDIFUNA, A. et al. Recombinant nucleocapsid protein is potencially an inexpensive, effective serodiagnostic reagent for infectious bronchitis virus. J Virol Methods, v.70, p.3744, 1998. Disponível em: <http://www.ncbi.nlm.nih.gov/pmc/ articles/PMC404667/>. Acesso em: 08 set. 2007. doi: 10.1016/ S0166-0934(97)00170-5.

SAPATS, S.I. et al. Generation of chicken single chain antibody variable fragments $(\mathrm{scFv})$ that differentiate and neutralize infectious bursal disease virus (IBDV). Arch Virol, v.148, p.497-515, 2003. Disponível em: <http:// www.springerlink.com/content/0tn781m67t4uw19p/>. Acesso em: 23 ago. 2007. doi:10.1007/s00705-002-0931-2.
SAPATS, S.I et al. Chicken recombinant antibodies specific for very virulent infectious bursal disease virus. Arch Virol, v.151, p.1551-1566, 2006. Disponível em: <http:// www.springerlink.com/content/547h316843p08023/>. Acesso em: 23 ago. 2007. doi: 10.1007/s00705-006-0729-8.

SEAH, J.N. et al. Localization of linear B-cell epitopes on infectious bronchitis virus nucleocapsid protein. Vet Microbiol, v.75, p.11-16, 2000. Disponível em: <linkinghub.elsevier.com/ retrieve/pii/S0378113500002029>. Acesso em: 14 set. 2009. doi:10.1016/S0378-1135(00)00202-9.

SEO, H.S. et al. The carboxyl-terminal 120 residue polypeptide of infectious bronchitis virus, nucleocapsid induces cytotoxic $\mathrm{T}$ lymphocytes and protects chicken from acute infection. J Virol, v.71, p.7889-7894, 1997. Disponível em: <http:// jvi.asm.org/cgi/content/abstract/71/10/7889>. Acesso em: 24 out. 2009. doi: 0022-538X/97/\$04.0010.

WILLIAMS, A.K. et al. Comparative analysis of the nucleocapsid genes of several strains of infectious bronchitis viruses and other coronaviruses. Virus Res, v.25, p.213-222, 1992. Disponível em: <linkinghub.elsevier.com/retrieve/pii/ 016817029290135V>. Acesso em: 15 jul. 2008. doi:10.1016/ 0168-1702(92)90135-V. 